\title{
AN EMPIRICAL STUDY OF UNIVERSITY WEBSITES
}

\author{
Marzie Astani, Winona State University, mastani@winona.edu \\ Mohamed A. Elhindi, Melhindi@SOUTHEASTMN.EDU
}

\begin{abstract}
For many organizations the website has been used as a tool for inter- and intra-organizational exchange. Since universities and colleges have started to use their websites as a student recruiting means, an effective website design is very important for higher education institution to attract students. This research explores the effectiveness of university websites. Some recommendations are made based on the findings.
\end{abstract}

Key Words: Website characteristics, University websites, Effective website design

\section{INTRODUCTION}

The growth of e-commerce has resulted in the interest of assessing the success of websites. This interest has been the driving force for studies investigating the determinants of an effective business website and how they can be measured. Several research studies have investigated the characteristics of a good business website $(4,13,14$, 20, 21, 25). Unfortunately, non-business organizations have been generally neglected in this process. Among the few studies focusing on nonbusiness organizations is Ceaparu and Shneiderman's research focusing on state government websites (5). They made several recommendations to improve information delivery and effectiveness of websites. Higher education institutions are among the nonbusiness organizations that need to be concerned about their website functionality and effectiveness. Just recently higher education institutions have started to pay attention to their websites' effectiveness and view them as a recruiting tool to attract students. But clearly there is a lack of sufficient studies investigating university websites design effectiveness.

Whether an organization is a business or nonbusiness, all experts agree that its website needs to be customer-centric $(10,13,14)$. This means that the website must be designed to meet the needs of a target audience. However, a number of factors play crucial roles in developing a good website. Having an inviting website that is easy to navigate and provides necessary information is vital to any organization. Web surfers have high expectations regardless of whether they are online for work or personal reasons. As a result, an organization, whether it is a business company or an educational institution, needs to be very careful about the image that is projected through its website. The educational institutions know that parents and high school students use the Internet as an initial tool to shop around for the best college. A major concern of these educational institutions should be whether their websites are projecting their schools effectively. The goal of these organizations should be to effectively present their academic offerings and opportunities through their websites.

No empirical study has been done to substantiate whether university websites are effective. The focus of this study is to explore the effectiveness of universities' websites based on characteristics that have been identified in the literature. The research question is whether university/college website designs are effective in attracting the target audience and effectively presenting relevant information. To answer this question, the websites of the top 50 colleges and universities (as rated by U.S. News \& World Report) are rated and the results are analyzed. Thus, the study is designed to provide insights about university websites' effectiveness. The research objective is to help educational institutions to achieve their goals by designing effective websites.

Next the literature review is presented, followed by the research methodology. Finally, the research results and conclusions/recommendations are presented. 


\section{LITERATURE REVIEW}

Educational institutions were among the first organizations to develop websites. In their earlier days, the goal was to simply have a presence on the web. Now, many colleges and universities are attempting to include a strong content combined with information about the school and its educational resources (23). According to Lynch and Horton (10), there are two parts in planning a website: 1) determine the goals and resources needed to achieve them, and 2) specify the target audience, site details, technology needed, and an assessment of the results. Thus, first, developers need to determine what the organization wants to accomplish on the web. For example, does it want to increase student recruitment or provide a teaching resource for lectures? Next, they must think about the audience and their requirements. A university website has two types of audiences. The primary audience is academic, general staff and students. The secondary audience is the general public and other educational institutions (16).

Although a well-designed website should accommodate a range of users' skills and interests, the key to a successful website is to understand the target audience and meet their needs. Ironically, those very users are the people least likely to be present and involved when the site is designed and built (16). In a marketing survey of 15,000 collegebound high school students, done on behalf of various colleges and universities, the results showed an unexpected increase in usage of the Internet among this segment of population. The survey indicated that the higher achieving students use the Internet more than their peers to search for colleges (19).

According to Steele (19), there is ample evidence to suggest that more and more educational institutions are using the Internet as a tool to recruit students. Regrettably, higher education institutions have failed to meet prospective students' college search requirements; rather their websites are geared for the campus community. Steele concludes that colleges have been passive sources of information and need to increase their communication with potential future students. He explains that, currently, students must go through many pages of information to find what the school has to offer. The importance of this issue is emphasized by the statistics showing that a typical student will not spent much time on a website if he/she doesn't find the information quickly. Each month, 17.3 million children and teens use the Internet and spend only 8 seconds viewing a website to determine whether it contains what they are interested in (19).

Many organizations are trying to design a website that would be attractive to the viewers. Building a website is not a one-time project with static content, rather an ongoing process which needs long-term editorial and technical management (10). But the difficulty is that many website designers have little knowledge of user interface design and usability engineering, therefore, wasting users' time and causing unnecessary traffic on the Internet.

\section{RESEARCH METHODOLOGY}

This research study is focused on the effectiveness of higher education institutions' websites. To assess the effectiveness of the university websites, we selected the top 50 universities in the U.S., based on the U.S. News \& World Report's ratings. The websites were rated by two experts. These raters had experience in conducting research studies on website design and developed several websites. The raters evaluated the top 50 university websites based on the characteristics that have been identified by Tarafdar and Zhang's (20) in their research study for successful website design. These characteristics have also been mentioned by other researchers in the literature (4, 16, 24, 25). We used Trafdar and Zhang's questionnaire for website evaluation (with minor modification) because it was pretested and used successfully by them. The raters discussed the websites' design characteristics and items before the evaluation took place to ensure that they had a common understanding about them. The websites were evaluated against the list of characteristics and each item was rated based on a 5-point Likert Scale. Each evaluator used the same computer for evaluating the websites to guard against differences for infrastructure reasons.

In their research, Tarafdar and Zhang (20) identified successful websites characteristics as: information 
content, navigation, usability, customization, download speed, and security. The website evaluation was done independently by each rater and completed over the course of three weeks. We considered the mean values of the two sets of ratings for each website as values of the evaluations for each item in the questionnaire.

\section{FINDINGS AND DISCUSSIONS}

The summary of the ratings for the university websites are presented in Tables 1 and 2. The first table shows the mean rating for every item in the questionnaire. The average ratings for website characteristic are shown in Table 2. It is evident that the universities have been making efforts to design good websites to attract students.

An important characteristic of a website is content. Experts believe that it is the content that brings users to a website (7). They suggest that a more valuable, dynamic, and updated content can attract more viewers. Researchers agree that the content should be easy to read and comprehend, relevant to the purpose of the website, and adequately in-dept (3, 9, 11). A typical user will not spend time reading long passages of text on-screen; therefore, the long text needs to be divided into discrete chunks of information in a logical way using the hierarchy to structure relationships among chunks. This needs to be done carefully to make sure that content camouflage is avoided. This means that the message should not be buried deep in the hierarchy of a site's structure; rather it should be two clicks away (18). Less critical information should be put at the bottom of the page and a text-only option needs to be offered for people who are using a slow network connection or are impatient (15).

The results of this study show that universities have been presenting information content well. The overall average rating for information content for the websites is close to 4 on the scale of $1-5$, which is indicative of effectiveness, although they have room to improve. Specifically, as shown in Table 1, the universities need to work on updating the information (INFO4, rating of 3.15), organizing the information systematically (INFO8, rating of 3.57), and designing better layout of the information (INFO10, rating of 3.5), so that the information can be located easily (INFO6, rating of 3.33). The university websites present a high range of information (rating of 4.38), which is not surprising.

Table 1 - Design Characteristics of Websites

\begin{tabular}{|l|l|l|}
\hline Characteristic & lomponent & Mean \\
\hline \multirow{5}{*}{$\begin{array}{l}\text { Information } \\
\text { Content }\end{array}$} & INFO1 - The range of information is high & 4.38 \\
\cline { 2 - 3 } & INFO2 - The information is applicable to the website's activities & 4.05 \\
\cline { 2 - 3 } & INFO3 - The information is detailed & 4.19 \\
\cline { 2 - 3 } & INFO4 - The information is current & 3.15 \\
\cline { 2 - 3 } & INFO5 - The information is accurate & 4.09 \\
\cline { 2 - 3 } & INFO6 - It is easy to locate the information & 3.33 \\
\cline { 2 - 3 } & INFO7 - The information is useful & 3.89 \\
\cline { 2 - 3 } & INFO8 - The information is systematically organized & 3.57 \\
\cline { 2 - 3 } & INFO9 - The meaning of the information is clear & 3.83 \\
\cline { 2 - 3 } & INFO10 - The layout of the information is easy to understand & 3.5 \\
\hline \multirow{5}{*}{ Navigation } & NAV1 - There are meaningful links & 4.17 \\
\cline { 2 - 3 } & NAV2 - The description of the links on the website is clear & 3.83 \\
\cline { 2 - 3 } & NAV3 - The links are consistent & 3.18 \\
\cline { 2 - 3 } & NAV4 - The arrangement of the different links is easy to understand & 3.37 \\
\cline { 2 - 3 } & NAV5 - The use of redundant hyperlinks makes it easy to navigate the website & 3.17 \\
\hline \multirow{5}{*}{ Usability } & USAB1 - The website is entertaining & 3.07 \\
\cline { 2 - 3 } & USAB2 - The website is exciting and interesting & 3.07 \\
\cline { 2 - 3 } & USAB3 - The website is easy to use & 3.4 \\
\cline { 2 - 3 } & USAB4 - The use of multimedia is effective for my tasks at the website & 3.44 \\
\hline
\end{tabular}




\begin{tabular}{|l|l|l|}
\hline \multirow{4}{*}{ Customization } & USAB5 - The website has an attractive layout & 3.3 \\
\cline { 2 - 3 } & CUST1 - The website has personalization characteristics & 2.99 \\
\hline \multirow{3}{*}{$\begin{array}{l}\text { Download } \\
\text { Speed }\end{array}$} & SUST2 - The website offers customized information & 3.56 \\
\cline { 2 - 3 } & $\begin{array}{l}\text { SPD2 - The speed of display between pages is high } \\
\text { displayed on my computer }\end{array}$ & 4.42 \\
\cline { 2 - 3 } & SPD3 - The rate at which the information is displayed is fast & 4.31 \\
\hline \multirow{3}{*}{ Security } & SEC1 - The website has provisions for user authentication & 4.16 \\
\cline { 2 - 3 } & $\begin{array}{l}\text { SEC2 - The website has provisions for a secure monetary transaction (for instance, } \\
\text { Verisign) }\end{array}$ & 3.89 \\
\cline { 2 - 3 } & SEC3 - The website has an information policy & 3.46 \\
\hline
\end{tabular}

Another characteristic of a website is the navigation. A logical and successful website organization matches the users' expectations and will allow them to make predictions about where to find information. They should make visitors feel comfortable exploring the website $(5,10,13,23)$. Any factor that affects the ease of navigation, such as the manner information is arranged in the design, layout and sequencing, number and effectiveness of hyperlinks, and overall website organization, relates to the navigation characteristic $(14,17)$. One of the difficulties that people have as they browse through a website is navigational problems, meaning they get lost within the structure. In a study (2) shows that as many as $66.8 \%$ of users have trouble finding the information they need. In a good website design, the basic navigation links should be present consistently on every page in the same location. Measures of flexibility need to be embedded into a site to let visitors use their past experience from familiar pages for unfamiliar ones. Misleading website structures could result in frustrated users. The results of this study (Table 1) show that the university websites lack consistency in the links (NAV3, rating of 3.18), the arrangement of different links are not easy to understand (NAV4, ratings of 3.37), and they don't provide redundant hyperlinks to make website navigation easy (NAV5, ratings of 3.17).

Usability is another website characteristic that relates to the ease of use. Experts agree that the website design should make it fun and visually attractive to the visitors. Flexibility and interesting features such as search engine and graphics can make the experience easier and enjoyable for viewers $(1,11)$. Although some of the universities in our sample used multimedia to make it fun for the visitors to browse the website, the overall average rating of 3.3 ( Table 2) shows that a lot of improvement is needed. This characteristic of websites is especially important for traditional students.

Table 2 - Average Ratings of Website Characteristics

\begin{tabular}{|l|l|}
\hline Website Characteristic & Grand Mean \\
\hline Information Content & 3.8 \\
\hline Navigation & 3.5 \\
\hline Usability & 3.3 \\
\hline Customization & 3.3 \\
\hline Download Speed & 4.3 \\
\hline Security & 3.3 \\
\hline
\end{tabular}

Personalization and customizing to specific groups of visitors is another important aspect of a website design $(6,8)$. This is a website capability that allows users to return to specific information and make the interaction with the website easy. In this study, the overall average rating of 3.3 for customization shows that this capability of universities' websites needs to be improved, especially in the personalization aspect.

Technical properties of websites include provisions such as security and overall technical reliability of the website. By definition, the website capability that allows user authentication is called security $(12,22)$. The overall technical reliability, which depends on the underlying IS infrastructural platform, defines the access speed (how fast the website's pages are downloaded and displayed) and the accessibility and availability of the website. The results of this research indicate that universities have managed to design their websites so that the access speed is not compromised. The average rating of 4.3 for downloading pages and moving from one page to another shows this fact. The overall average rating of 
3.3 for the security characteristic of the websites involved in this study shows that the websites need to make improvement in this area.

\section{CONCLUSION}

In today's competitive market it is crucial that higher education institutions explore every avenue for recruiting new students. Today's media-savvy students have adapted to the current media-saturated environment by learning how to scan through massive amount of information quickly and locate the information they are searching for. Universities and colleges have begun to use their websites as a recruiting tool (19). Therefore, higher education institutions need to address the needs of their target audience and design effective websites so that they will attract students.

This study attempted to shed some light on the university websites' situation. We selected the top 50 universities based on the U.S. News \& World Report's ratings for investigation. Next, we used the website characteristics that were identified in the literature (20) to rate their websites to assess the effectiveness. The results were analyzed to show the overall weaknesses and strengths of the university websites involved in the study. The results show that the universities have succeeded in presenting a high range of information that is relevant and applicable to their website. However, they need to improve in updating their information and presenting it in a layout that will make it easier for users to locate the information of interest. Also, they have been careful about the download speed since the results indicate that pages can be downloaded at a good speed. However, the universities need to improve in the areas of navigation, usability, customization, and security. The websites' navigational components were rated average for consistency of links, having redundant links for easier navigation, and arrangement of links that would be easy to understand. The usability components of these website, that is the attractiveness, getting the user excited about the website, ease of use, and having attractive layout were rated average also. In addition, the websites need to offer better customized information. The security of the university websites also needs improvement.
Finally, it needs to be emphasized that the sample selected for this study was the top 50 universities in the country. We can speculate that these universities websites were perhaps the best of the breed; therefore, the higher education institutions need to consider making significant improvements in their websites. We hope that ultimately colleges and universities can improve their web sites and increase recruitment of prospective students. Further research needs to be done to help universities to achieve this objective.

\section{REFERENCES}

1. Agarwal, R. and Venkatesh, V. (2002). Assessing a Firm's Web Presence: A Heuristic Evaluation Procedure for the Measurement of Usability. Information Systems Research, V. 13, (2), pp. 168-186.

2. Bernard, Michael. (2002). Criteria for Optimal Web Design. Software Usability Research Laboratory, http://psychology.wichita.edu/optimalweb/stru cture.html, (accessed February 6, 2003).

3. Bruce, H. (1998). User Satisfaction With Information Seeking on the Internet. Journal of the American Society of Information Sciences. V. 49, (6), pp. 541-556.

4. Cappel, J. and Huang, Z. (2007). A Usability Analysis of Company Websites. Journal of Computer Information Systems. V. XLVIII, (1), pp. 117-123.

5. Ceaparu, I and Shneiderman, B. Improving Web-based Civic Information Access: A Case Study of the 50 U.S. States. ftp://ftp.cs.umd.edu/pub/hcil/ReportsAbstracts-ibligraphy/2002-12html2002-12.pdf, (accessed February 6, 2003).

6. Chen, P. and Hitt, L.M. (2002). Measuring Switching Costs and the Determinents of Customer Retention in Internet-Enabled Businesses: A study of the Online Brokrage Industry. Information Systems Research. V. 13, (3), pp. 255-274.

7. Dewan, R. Freimer, M. and Zhang, J. (2002). Management and Valuation of AdvertisementSupported Web Dites. Journal of Management Information Systems. V. 19, No 3, pp. 87-98.

8. Greer, T.H. and Murtaza, M.M. (2003). Web Personalization: The Impact of Perceived Innovation Characteristics on the Intention to Use Personalization. Journal of Computer Information Systems. V. XLIV, (3), pp. 50-53. 
9. Katterattanukul, P. and Siau, K. (1999). Measuring Information Quality of Web Sites: Development of an Instrument. Proceedings of the $20^{\text {th }}$ International Conference on Information Systems. Pp. 279-285.

10. Lynch, P. and Horton, S. (March 2002). Web Style Guide: Basic Design Principles for Creating Web Sites, Second Edition. Yale University Press.

11. McKinney, V.; Yoon, K. and Zahedi, F. (2002). The Measurement of Web-Customer Satisfaction: An Expectation and Disconfirmation Approach. Information Systems Research. V. 13, (3), pp. 296-315.

12. McKnight, D.H., Choudhury, V. and Kacmar, C. (2002). Developing and Validating Trust Measures for e-Commerce: An Integrative Typology. Information Systems Research. V. 13, (3), pp. 334-359.

13. Nielsen, J. (May 1999). “Top Ten Mistakes” Revisited Three Years Later. Nielsen’s Alertbox,. http://www.useit.com/alertbox/990502.html, (accessed February 20, 2003).

14. Nielson, J. (2000). Designing Web Usability. Indianapolis, IN. New Riders.

15. Pretzer, Mary. (1998). Common Sense Web Page Design: Cleaning Out the COB Webs. Rural Telecommunications, Vol. 17, (4).

16. Raward, Roslyn. (2001). Academic Library Website Design Principles: Development of a Checklist. Australian Academic \& Research Libraries, V32, i2, p.123-134.

17. Shchiglik, C. and Barns, S.J. (2004). Evaluating Website Quality in the Airline Industry. Journal of Computer Information Systems. V. XLIV, (3), pp. 17-25.

18. Showker, Fred. (1998). Removing Barriers. Electronic Publishing, V. 22, (5).

19. Steele, Jonathan. (2002). The Media Omnivores: Understanding College-bound Students and Communicating with Them Effectively. NACAC Journal of College Admission, (175). http://www.dehne.com/news research/researc h_media_omnivores. (accessed February 6, 2003).

20. Tarafdar, M. and Zhang, J. (2005-2006). Analysis of Critical Website Characteristics: A Cross-Category Study of Successful Websites. Journal of Computer Information Systems. V. XLVI, (2), pp. 14-24.

21. Tarafdar, M. and Zhang, J. (2007-2008). Determinants of Reach And Loyalty - A Study of Website Performance And Implications For
Website Design. Journal of Computer Information Systems. V. XLVIII, (2), pp. 16-24.

22. Torkzadeh, G. and Dhillon, G. (2002). Measuring Factors that Influence the Success of Internet Commerce. Information Systems Journal. V. 13, (2), pp. 187-204.

23. Weinstein, Peter. (1997). Tips and tools for building a school Website. Technology \& Learning. V. 17, (4), p 25-37.

24. Van Schaik, and Ling, J. (2007). Design Parameters of Scales For Web Sites. ACM Transactions on Computer-Human Interaction. V. 14, (1), pp. 1-35.

25. Yeung, W. and Lu, M. (2004). Gaining Competitive Advantages Through A Functionality Grid For Website Evaluation. Journal of Computer Information Systems. V. XLIV, (4), pp. 67-77 